\title{
Therapeutic comparison between treatments for Vulvar Lichen Sclerosus: study protocol of a randomized prospective and controlled trial
}

Renata A. Belotto ${ }^{1,2}$, Maria Cristina Chavantes 3 , João Paulo Tardivo ${ }^{4}$, Roberto Euzébio dos Santos², Raquel Civolani Marques Fernandes ${ }^{2}$, Anna Carolina Ratto Tempestini Horliana', Christiane Pavani ${ }^{1}$ and Daniela Fátima Teixeira da Silva ${ }^{{ }^{*}}$

\begin{abstract}
Background: Vulvar lichen sclerosus (VLS) is a lymphocyte-mediated disease of unknown etiology that can cause intense itching as well stenosis, hindering the evacuation and urination. It can also limit the sex life due to severe local pruritus, pain and dyspareunia (pain during sexual intercourse). The standard treatment for this disease is the use of topical corticosteroids to reduce the clinical symptoms and to try to increase disease-free intervals. Photodynamic therapy (PDT), a treatment that associates a light radiation with a photosensitizing agent and photobiomodulation (PBM) are therapies that can promote effective immunomodulatory responses at the application site by means of photophysical and photochemical phenomena from the molecular to the systemic level, which promote their use in chronic dermatoses. The aim is to compare the effects of PDT, PBM, and topical corticosteroid in VLS evaluating clinical, histological, immunohistochemical and spectroscopic responses.
\end{abstract}

Methods: The study is prospective, randomized and controlled, in a population of 60 women with histological diagnoses of VLS. There will be 3 treatments groups: PDT, PBM and topical corticosteroid (control group), where will be allocated by randomization 20 patients in each one. The clinical course will be monitored by measuring local temperature, itching, atrophy, and the area of the lesion. Histologically, the slides will be classified and will have the ordering of collagen fibers quantified. Immunohistochemical analysis will be done using the markers IFN- $\gamma$, TGF- $\beta$, CD4, CD8, IL-1, p53 and Ki-67. Finally, the spectroscopic evaluation will be done by reflectance. Descriptive and inferential statistical analyses will be conducted to compare the groups and make associations between different responses. The study is an open-label for patients with active symptomatic disease with a period of 1 year follow-up to determine the rate of recurrence in each groups.

Discussion: The immunological effects of PDT and PBM are described by several authors in inflammatory skin diseases, stimulating the production and organization of the associated collagen. Thus, it is reasonable to determine the efficacy and safety of these new treatments in VLS, in comparison to the control group, analyzing the recurrence time, the impact on the optical properties of the skin, and the benefit to patients.

Trial Registration: ClinicalTrials.gov: NCT02416531.

Keywords: Collagen, Photobiomodulation, Photodynamic Therapy, Methylene blue, Corticosteroid

\footnotetext{
* Correspondence: fatesi@uol.com.br; dfteixeira@uni9.pro.br

${ }^{1}$ Postgraduate Program in Biophotonics Applied to Health Sciences, Nove de

Julho University/UNINOVE, 249 Vergueiro Street, Liberdade, São Paulo, SP

01504-001, Brazil

Full list of author information is available at the end of the article
}

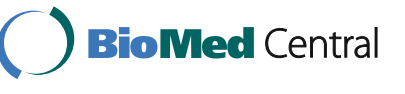

(c) The Author(s). 2017 Open Access This article is distributed under the terms of the Creative Commons Attribution 4.0 International License (http://creativecommons.org/licenses/by/4.0/), which permits unrestricted use, distribution, and reproduction in any medium, provided you give appropriate credit to the original author(s) and the source, provide a link to the Creative Commons license, and indicate if changes were made. The Creative Commons Public Domain Dedication waiver (http://creativecommons.org/publicdomain/zero/1.0/) applies to the data made available in this article, unless otherwise stated. 


\section{Background}

The pathogenesis of vulvar lichen sclerosus (VLS) is idiopathic, but some theories are described, such as the genetic theory, in which it is believed that about $22 \%$ of the lichen can be inherited [1]. There is the theory of hormonal changes due to decreased levels of dihydrotestosterone and androstenedione, and reduced activity of the enzyme $5 \alpha$ reductase [2]. Autoimmune factors and oxidative stress have also been accepted due to the high association with autoimmune disease and the presence of highly specific antibodies against the extracellular matrix protein (ECM 1) [3]. Researchers have reported an autoimmune phenotype characterized by increased levels of Th1-specific cytokines, dense infiltration of $\mathrm{T}$ cells, and increased BIC/miR-155 expression [4]. Even though recent work has shown for the first time that vulvar lichen sclerosus is associated with 5-hydroxymethylation and altered expression of IDH enzymes, providing evidence for an epigenetic factor in the pathogenesis, literature is still reticent to establish it as an autoimmune disease [5]. Finally, there is the infectious theory of local factors, whose trauma and friction have been described, but as yet without evidence [6].

Vulvar lichen sclerosus affects the genital skin causing intense itching, whitening and atrophy, and this can cause stenosis, resulting in vulvodynia, pain on urination and bowel movements [7, 8]. It is the second leading cause of non-neoplastic vulvar disease, and is considered the most common cause of chronic vulvar disease with an estimated prevalence of 1:30-1:1000 [9]. The genital form is 5 to 10 times more frequent in women over 40 years and affected females outnumber males by 10:1 [10]. Anogenital involvement is $85 \%$ and extragenital is $15 \%$ [11]. The disease can affect children (1:900) and the clinical aspect is similar to that in adults, thus requiring long-term monitoring [11].

VLS has a malignant potential of around $4 \%$, and is, therefore, considered as a means of vulvar carcinogenesis, with a recorded incidence of $32 \%$ to $76 \%$ of squamous cell carcinoma of the vulva adjacent to the lichen area $[3,7,12,13]$.

The diagnosis is clinical, but there may be uncertainty in the early stages of the disease and the main differential diagnoses are psoriasis, lichen planus, lichen simplex chronicus and benign mucous-membrane pemphigoid. A biopsy is recommended in cases that do not respond to treatment with topical corticosteroids, ulcerated lichen, or on suspicion of an invasive lesion [7, 14].

There is still no cure for VLS, so treatment is aimed at the symptoms, especially the vulvar itching, in order to prevent scarring and vulvar anatomical deformity, and to improve the quality of the sex life of patients, whom often report dyspareunia (painful intercourse), decreased orgasm and intercourse frequency compared to women who are not affected $[9,10]$. Treatment is conservative using topical products [12], the gold-standard therapy is based on high-potency corticosteroid [15].

As the standard treatment can cause side effects, such as atrophy and permanent stretch marks, and still does not provide the cure, trying to find new therapies, per se, is an important challenging for the clinical practice. Effective alternatives that improve the excruciating skin process and optimize the quality of life in affected patients should be studied, and this is the motivation for this work, using photodynamic therapy (PDT) or photobiomodulation (PBM). There is no dosimetric protocol established for the treatment of VLS with PDT, nor with PBM. According to the literature, energy densities range from 9 to $150 \mathrm{~J} / \mathrm{cm}^{2}$ and power densities from 40 to $700 \mathrm{~mW} / \mathrm{cm}^{2}$ [16-21], without mentioning the studies that do not report the dosimetry used [22, 23].

There are few references in the literature about the action of PDT in vulvar lichen sclerosus [16-20, 22, 23], and till now there is no reference concerning PBM, although the anti-inflammatory and healing effects of $\mathrm{PBM}$ are documented in various medical and biological applications [24]. It is hoped that a prospective clinical study would contribute to more effective action in the control of this chronic skin disease, and possible understanding the mechanisms of action of these treatments.

It will be performed a comparative study among clobetasol propionate, photodynamic therapy, and photobiomodulation in patients with vulvar lichen sclerosus, using the following analyses:

a) Clinical-by measuring the local temperature, pruritus, clamping and area of the lesion;

b) Histological—by staining with hematoxylin \& eosin;

c) Immunohistochemical-using the markers IFN- $\gamma$, TGF- $\beta$, CD4, CD8, IL-1, p53, and Ki-67;

d) Spectroscopic-by in vivo reflectance of skin.

\section{Methods/Design}

The study is prospective, randomized, controlled, and conducted with 60 patients enrolled at Hospital Pérola Byington, São Paulo. The research will be undertaken in partnership with gynecologist Renata Ap. Belotto, CRM 59284.

After reading, understood and signed the Free and Informed Consent, the patients will undergo a biopsy for histological confirmation of VLS, samples for laboratory tests will be collected at the beginning and end of the study: complete blood count, fasting glucose, free T4, TSH, urea, creatinine, sodium, potassium and plasma cortisol.

\section{Inclusion criteria}

The participants in this study will be only adult female (aged over 18 years), histological diagnosed 
with vulvar lichen sclerosus with a normal level of cortisol, confirmed by blood test.

\section{Exclusion criteria}

Patients with any kind of ongoing cancer and/or AIDS or coagulopathy; pregnant or breastfeeding women; patients using corticosteroids, immunosuppressants or anticoagulants; patients with renal, hepatic or pulmonary-cardiovascular failure; patients who have undergone any kind of organ transplantation in the last three years.

\section{Randomization and dosimetry}

A researcher not involved in the study will divide the patients into three groups by randomized order (Minitab 16, EUA). Then, opaque envelopes randomly containing information about application of photobiomodulation, photodynamic therapy or corticosteroid will be labelled with sequential numbers. The researcher responsible for treatments will open the first envelope and perform the procedure written therein. The internal contents will be revealed only after statistical analysis.

The dosimetry to be used in this study is based on a pilot clinical study performed by our group, which followed the recommendations from ASLMS [21]. In brief, the aim was to compare the effects of PBM and topical corticosteroid in VLS evaluating clinical response, itching, skin thickness (atrophy), and recurrence of disease after treatments. The study was prospective, randomized, and controlled in 20 women. CAAE number of Research Ethics Committee: 34,715,314.6.3001.0069. Corticosteroid group: clobetasol propionate $0.05 \%$ ointment applied once daily at a dose of $1 \mathrm{~g}$ /application for 4 weeks. PBM group: methylene blue $0.01 \%$ intralesional, laser $\lambda=660 \mathrm{~nm}$, $P=100 \mathrm{~mW}, I=510 \mathrm{~mW} / \mathrm{cm}^{2}, \mathrm{E}=4 \mathrm{~J}$, exposure radiant $=20 \mathrm{~J} / \mathrm{cm}^{2}, t=40 \mathrm{~s}$, once a week for 4 weeks. The variation in intensity of itching was compared between groups, the corticosteroid group reduced the itching at $83.75 \%$, and the PB group decreased $50.00 \%$. The corticosteroid group showed significant variation in the skin thickness relative to $\mathrm{PB}(p=0.006)$. This group had a reduction in thickness of the skin $-27.51 \%$, while in $\mathrm{PB}$ group showed an increase of $49.07 \%$. The treatments were completed in December 2014 and until the month of
September 2015 in the corticosteroid group there was 7 patients with no symptoms, while in the PB group there was 6 patients. In the corticosteroid group, the first recurrence was two months after the treatment, while the PBM was only 4 months later.

The groups to be studied and their dosimetry are showed at Table 1.

The mode of application of photonic therapies will be by point, localized at 8 points of the vulva, as shown in Fig. 1.

Patients in the PDT group, upon arriving at the outpatient clinic, will be treated twice: first they will receive topical lidocaine gel $2 \%$ on the vulva and will return to the waiting room. Second: after 15 min, methylene blue with lidocaine will be injected, in a 1 to 1 ratio, at 8 points of vulva and so as to perform the PDT immediately. This procedure will be performed for the exact reason of minimizing the pain of the injection.

\section{Analyses}

The control group (topical corticosteroid) will not be seen weekly because the standard treatment is performed by the patients themselves, in their own homes, for 30 days as recommended by the International Society for the Study of Vulvar Disease (ISSVD). In this way, all groups (GC, GPDT and GPBM) will receive treatment for 30 days and as biopsies before and after these 30 days will be compared. The study will be an open-label for patients with active symptomatic disease with a period of 12 months follow-up to determine the rate of recurrence in each arm.

\section{Clinical}

The temperature of the vulva will be measured with an infrared thermographic camera $\left(\mathrm{C} 2, \mathrm{FLIR}^{\oplus}\right.$, Nashua/ $\mathrm{NH}$, USA), which enables simultaneous measurement of the entire target area without physical contact. Measurements will be recorded as images in all sessions before, during, and after irradiation to observe the thermal fluctuation in the procedures.

In each session, the patients will be asked about the intensity of vulvar itching to assess its severity and duration, before and after irradiation, according to a visual analogical scale.

Table 1 Characteristics of the groups

\begin{tabular}{|c|c|c|c|}
\hline Group & Number & Treatment & Parameters \\
\hline GC & 20 & Corticosteroid over the whole vulva & $\begin{array}{l}\text { Clobetasol propionate } 0.05 \% \text { ointment applied once } \\
\text { daily at a dose of } 1 \mathrm{~g} / \text { application ( } 1 \mathrm{~g} \text { sachets) for } 4 \text { weeks }\end{array}$ \\
\hline GPDT & 20 & $\begin{array}{l}\text { Localized photodynamic therapy at } \\
8 \text { points of the vulva }\end{array}$ & $\begin{array}{l}\text { Methylene blue } 0.01 \% \text { intralesional + lidocaine } 2 \% \text {, } \\
\lambda=660 \pm 10 \mathrm{~nm}, P=100 \mathrm{~mW}, I=510 \mathrm{~mW} / \mathrm{cm}^{2} \\
\mathrm{E}=4 \mathrm{~J}, \mathrm{RE}=20 \mathrm{~J} / \mathrm{cm}^{2}, t=40 \mathrm{~s} \text {, once a week for } 4 \text { weeks }\end{array}$ \\
\hline GPBM & 20 & $\begin{array}{l}\text { Localized photobiomodulation at } \\
8 \text { points of the vulva }\end{array}$ & $\begin{array}{l}\text { The same parameters as for GPDT, except for the methylene } \\
\text { blue, once a week for } 4 \text { weeks }\end{array}$ \\
\hline
\end{tabular}

Laser parameters: $\lambda$ wavelength, $P$ power, I irradiance, $E$ energy, RE radiant exposure, $t$ exposure time. Laser: Photon Laser III (DMC ${ }^{\circ}$ São Carlos/SP, Brazil). 


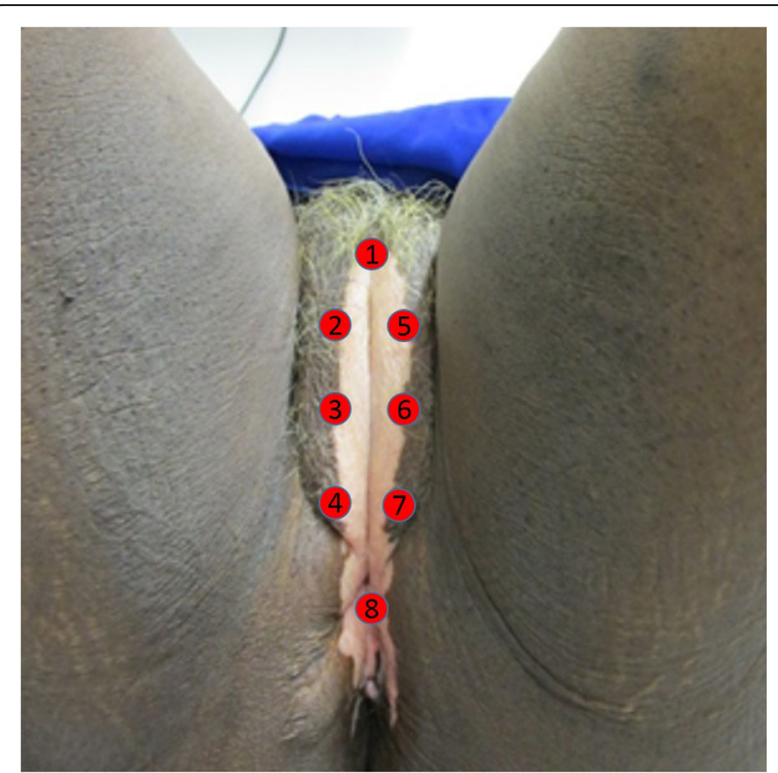

Fig. 1 Photo of the vulva highlighting the 8 points of irradiation for PDT and PBM

The vulvar skin clamping to evaluate the trophism will be done before irradiation at each session, using a digital caliper (Insize ${ }^{\oplus}$, São Paulo/SP, Brazil), transversely and longitudinally in relation to the labia majora.

The area of the lesion will be monitored with a digital camera at every session (EOS Rebel T5, Canon ${ }^{\oplus}$, Melville/NY, USA), before irradiation. To facilitate measurements, a metric scale will be placed on all vulvas for the photos. The areas of the lesions will be quantified using ImageJ software (National Institutes of Health, Maryland, USA).

The temperature, the intensity of itching, the clamping and the photographic images will be recorded for the patients of the GPDT and GPBM groups weekly for 30 days and for the GC group these measures will be done at first and 30th day.

If patients still report discomfort or undesirable symptoms from LEV after 30 days of treatment, they will continue with the same clinical protocol. If 60 days after the initiation of treatment they still remain symptomatic, the treatment that clinically appears to be better will be offered.

\section{Histological}

The biopsies will be performed at two points: at baseline to confirm the VLS and subsequent inclusion in the research protocol, and at the end of 30 days to investigate the prognosis after treatment. The skin fragments will be placed immediately in vials containing $4 \%$ buffered formalin, identified with the patient's numbers and names, in accordance with the standard routine of the hospital, and sent to the Pathology Laboratory at the
Hospital Pérola Byington. There will be no mention of the study group on the vials, so the analysis will be performed blind by one experienced pathologist.

Three sets of histological sections will be processed. One set will be for staining in hematoxylin and eosin in order to recognize cells and their components and to make inferences on the histology of the tissue under an ordinary optical microscope. The slides of each patient will be classified and the classifications will be assigned scores so that they can be statistically analyzed.

Another set will not be stained and will be deparaffinized for analysis of the ordering of collagen fibers under a polarized light microscope, according to an already established protocol [25]. The third and final set of histological sections will be used for the immunohistochemical technique, which is described in the next subsection. It is emphasized that the method used in the analysis of collagen ordering will be quantitative, by measuring the optical birefringence $(\Delta n)$ of the samples, in nanometers.

\section{Immunohistochemical}

Once deparaffinized, the sections will be subjected to antigen retrieval, endogenous enzyme blocking, background blocking, incubations of antibodies, and counter-staining according to the instructions of the manufacturers of the IFN- $\gamma$, TGF- $\beta$, CD4, CD8, IL-1, p53, and Ki67 antibodies (Sigma-Aldrich ${ }^{\oplus}$, St. Louis/MO, USA and Cell-Signaling ${ }^{\oplus}$, Danvers/MA, USA). The cells that are positively stained by the immunohistochemical reaction will be counted by Image software (National Institutes of Health, Maryland, USA) by two independent pathologists without prior knowledge of the experimental groups.

\section{In-vivo reflectance spectroscopy}

A portable spectrophotometer (400-900 nm) comprising a light source and a fiber-optic probe (USB2000, OceanOptics ${ }^{\oplus}$, Dunedin/FL, USA) will be used directly on the surface of the vulvar skin in areas affected by VLS and in healthy areas of the same patients. Spectra will be taken in each session, just before the PDT and PBM. The patients in the corticosteroid group will have the spectrum recorded only twice-at baseline and after 30 days. Relative spectra will be obtained for the wavelengths corresponding to those of the therapeutic window, and the percentage of relative reflectance will be calculated.

\section{Statistical evaluation}

Using the $G^{*}$ Power software version 3.1.9.2, the calculus of power analysis was determined by choosing $\mathrm{F}$ tests for repeated measures, within-between interaction, since 3 groups will be studied, and each group will be measure before and after treatments. The effect size was determined using the formula [26]: 


$$
d=\frac{\text { largest }- \text { smallest }}{\left(\frac{\sigma}{\sqrt{n}}\right)^{2}}
$$

The largest and smallest mean values, as well as the standard deviation were taken from the pilot clinical study [21]. The $\alpha$ error was set at $5 \%$ and the $\beta$ error was set at $95 \%$. The $\mathrm{n}$ value is the number of groups, i.e., three. According to the $G^{*}$ Power, a sample of 20 patients per group will be required for a power of $88.7 \%$.

The profile of patients will be analyzed according to age, duration of disease, comorbidities and reported symptoms. A descriptive analysis will be conducted and presented by graph.

The clinical, histological, immunohistochemical, and spectroscopic findings will be submitted to inferential statistical analysis to verify the differences between the treatment groups. Associations between these results will also be analyzed. The significance chosen for the tests will be $95 \%$.

First, the statistical distribution of the data will be evaluated. If the data conform to a Gaussian curve, parametric tests will be used. Graphs will be constructed in accordance with the means and standard deviations of the data.

However, if the data is unsuitable for a normal distribution, they will be analyzed with nonparametric tests. Boxtype and quartile graphs, constructed according to the median of the results, will be used to present the data.

All data analysis will be performed using SPSS 22 Statistics software (IBM, USA).

\section{Global benefits for the patients}

The criterion for recurrence will be pruritus, because it is the main patient complaint. The expected optical change in the skin is a reduction in reflection; lichen sclerosus leaves the skin depigmented, i.e. white, which is the color that most reflects. Therefore, as the symptoms diminish, we expect the skin to become less white, meaning that reflection also diminishes. We expect photonic therapies to decrease pruritus as much as the corticosteroid and, in addition, to not decrease the thickness of the skin, avoiding stenosis and pain.

\section{Discussion}

The rare studies of PDT in intraepithelial neoplasia of the vulva have shown increased cytotoxic T lymphocyte in the treated area, as well as reduction in recurrence $[27,28]$. The immunological effects of PDT and PBM are also described by several authors in inflammatory skin diseases, stimulating the production and organization of the associated collagen $[24,25,29]$. Thus, it is reasonable to determine the efficacy and safety of these new treatments in vulvar lichen sclerosus, analyzing the recurrence time, the impact on the optical properties of the skin, and the benefit to patients by clinical, histological, immunohistochemical and spectroscopic aspects.

Since high-potency topical corticosteroids are the first line treatment for VLS, clobetasol propionate $0.05 \%$ ointment is currently considered the gold standard. Approximately $60 \%$ of patients experience complete remission of symptoms, with consequent elimination of fissures, erosions, and hyperkeratosis [15]. Its use is effective, but the atrophy of the skin, scars, and hypopigmentation are irreversible with its use. Typically, a thin layer of steroid (finger tip unit) is applied once or twice daily for 2 to 4 weeks, then being reduced to three times a week, till withdrawal of the product [9].

PDT is a photochemical technique, and has been a treatment option in some gynecological and skin diseases $[25,29]$. It consists of a combination of a photosensitizer and a light source, and these must be optically resonant. Its efficacy depends on the selectivity and retention of the photosensitizer, the intensity of the incident radiation, the transfer of excitation energy from the photosensitive agent and its oxidizing effect [30]. Specifically in VLS, its effectiveness has been varied, mainly due to the characteristics of the commonly used photosensitizers (methyl aminolevulinate and 5-aminolevulinic acid), which are topical, requiring periods ranging from two to five hours for sufficient production of porphyrin before the interaction with light $[17,21]$. The lack of standardization of the various physical parameters of the radiation (light source, power, exposure time, energy and power densities) also contributes to the partial success of this treatment modality [31]. Adverse effects are reported, such as erythema, burning, and discomfort, even a few hours after therapy. Therefore, the association with intralesional anesthetic is common [17, 21, 31]. Nevertheless, the beneficial effects on the VLS are outstanding, such as the relief of symptoms for up to 6 months and/or the absence of the lesion [16-20].

The few studies of VLS treatments applying PDT are described with 5-aminolevulinic acid, a precursor of the photosensitive agent protoporphyrin IX, or its methyl ester, which is more lipophilic. However, at physiological $\mathrm{pH}$, ALA forms zwitterions, which prevents its ability to cross biological barriers such as cell membranes, resulting in slow and non-homogeneous distribution in the target tissue, even as its high cost and phototoxicity [32].

On the other hand, methylene blue (MB) acting as the photosensitizer makes PDT more reasonable in clinical practice, especially in the Public Health System, since it has a high quantum yield of singlet oxygen and the ability to generate several radical species, it is highly photostable, easily eliminated from the body, presents minimal toxicity and low cost [33]. Moreover, the MB has an affinity for melanin, it is more lipophilic than ALA, actively binds to mitochondria and provides a mechanism for the reduction 
of the inflammatory response [34, 35]. The monomers and dimers of $\mathrm{MB}$ have distinct absorption spectra: the monomers have maximum absorption at $664 \mathrm{~nm}$ and the dimers at $590 \mathrm{~nm}$. It is known that in a $20 \mu \mathrm{M}$ aqueous solution there are only monomers present. A detailed review of the characteristics of $\mathrm{MB}$ can be found in the study of Tardivo et al. [36].

In PBM, the power density is not sufficient to induce biological activity dependent on the temperature increase, provided that the recommendations of the World Association for Laser Therapy (WALT) are followed [31]. It can be used with radiation sources that are coherent (lasers) or incoherent (lamps and LEDs). The basic biological mechanism that is currently accepted for explaining, although not completely, the effects observed in PBM is the absorption of red and infrared radiation by chromophores in mitochondria, in particular cytochrome c oxidase, and photoreceptors in the plasma membrane of cells, respectively [30]. The main reported effects are the reduction of pain and inflammation, optimization of tissue repair, tissue and nerve regeneration, and the repigmentation of skin lesions [24]. While these effects are desirable in the treatment of VLS, to date no work has been found associating it with PBM.

Nowadays we know that immunohistochemistry is an indispensable technique for solving differential diagnosis problems caused by basic routine staining of HE [32]. Although we know that the diagnosis of LEV is clinical, we insist to collect the biopsies so that we can cross-check the data (HE versus immunohistochemistry) for a better understanding of the disease and the mechanisms involved after the different therapies. We remember that VLS has a malignant potential of around $4 \%$, and is, therefore, considered as a means of vulvar carcinogenesis, with a recorded incidence of $32 \%$ to $76 \%$ of squamous cell carcinoma of the vulva adjacent to the lichen area.

Studies performed by different groups has promoted a basis for associating antibodies for IFN $-\gamma$ (interferon gamma), TGF- $\beta$ (transforming growth factor beta), CD4, CD8, IL-1 (lymphocyte activating factor), p53, and Ki67 with vulvar lichen sclerosus [3, 5, 13, 33, 34]. The study of these cytokines and proteins will add to the understanding the biological mechanism triggered by photonic therapies.

Cytokine IFN- $\gamma$ is the major interferon produced by lymphocytes stimulated by mitogens or antigens, and is related to immunoregulation. It is an inducer of IL-2 (interleukin 2), acting on the immune response profile of Th2 cells to Th1 cells, which control the homeostasis of the immune system. There are reports of increased IFN- $\gamma$ staining in the VLS epidermis compared with the healthy vulva and non-vulvar skin, suggesting that this disease shares the characteristics of a chronic wound [33].
TGF- $\beta$ protein plays a role in embryonic development, cell differentiation, hormone secretion, and immune function. Specifically during healing, it functions as a chemoattractant for neutrophils, macrophages and fibroblasts [35]. Although no difference has been found in the expression of TGF- $\beta$ between lichen sclerosus and healthy skin, there are no studies comparing this marker as a function of different therapies, nor of its association with collagen synthesis in VLS [36].

The CD4-CD8 ratio is the ratio of $\mathrm{T}$ lymphocytes expressing $\mathrm{CD} 4$ antigens to those expressing $\mathrm{CD} 8$ antigens. This value is usually assessed in the diagnosis and stages of diseases that affect the immune system. The expression of these markers was pronounced in the dermal infiltrate of VLS [4].

Cytokine IL-1 is a soluble factor produced by monocytes, macrophages and other cells that activates $\mathrm{T}$ lymphocytes and enhance their responses to mitogens and antigens. The biological effects of IL-1 include the ability to meet the requirements of macrophages necessary for activating $\mathrm{T}$ cells. The increased expression of this cytokine has also been reported in VLS [33].

Tumor-suppressant protein p53 is a nuclear phosphoprotein encoded by the p53 gene, and its normal function is to control cell proliferation and apoptosis. Ki-67 protein is present only in the active phase of the cell, making it a good marker for cell proliferation. Major expression of both markers was found in VLS, reflecting the risk of progression to malignancy $[3,13]$.

The demand for performing the challenging task of optically diagnosing and characterizing biological tissues can be attributed to the rapid development of laser applications in the field of medicine and, more recently, the use of LEDs (light-emitting diodes) [37]. Such applications require better understanding of the radiationtissue interaction, and thus of the optical changes caused by the biological target in the light passing through it (photodiagnostics) and also the optical changes caused by the light radiation in the tissue (phototherapy).

To make inferences regarding the tissue structure based on measured optical characteristics is a complex task. However, the challenge is tempting and promising due to the fact that the optical characterization of biological tissue contains valuable diagnostic information, to the extent that there is a measurable difference between normal and pathological states, including preventively [38].

When the optical properties of the skin are altered, specifically the absorption and scattering coefficients, the intensity of reflectance is affected. The measurement of reflectance spectra has, therefore, been used to obtain the optical characteristics of the skin in vivo [39, 40]. Thus, it is possible to quantitatively evaluate the effect of different agents on skin condition by analysis of the spectral reflectance [41]. 
There are no reports in the literature on the reflectance of skin affected by VLS, which can contribute not only to the understanding of the mechanisms of the proposed phototherapies, but also to an improved optical knowledge of the tissue as a function of biological changes related to the stage of VLS [42]. Thus, since the spectroscopic study in VLS is unprecedented, it was decided to use reflectance spectroscopy because it is the easiest method in vivo. If significant differences are found between the spectra of different groups or in one patient depending on the duration of treatment, another study will be proposed for more detailed investigation to obtain the reduced absorption and scattering coefficients in the spectral range of the therapeutic window.

\section{Abbreviations}

ECM 1: Extracellular matrix protein; ISSVD: International Society for the Study of Vulvar Disease; LEDs: Light-emitting diodes; MB: Methylene blue; PBM: Photobiomodulation; PDT: Photodynamic therapy; VLS: Vulvar lichen sclerosus; WALT: World Association for Laser Therapy

\section{Acknowledgements}

The authors would like to thank the Rosangela Itri, Maurício da Silva Baptista and Helena Junqueira by materials essential borrowed during the pilot study.

\section{Funding}

The authors would like to thank the Brazilian funding agency: grants \#2012/ 50680-5 and \#2015/05259-8, São Paulo Research Foundation (FAPESP).

\section{Availability of data and materials}

After the obtained results, all datasets that the conclusions of the manuscript rely will be deposited in publicly available repositories.

\section{Authors' contributions}

RAB it is the doctor responsible for the patients and the master student leading the research, and helped to draft the manuscript. MCC and JPT conceived of the study. RCMF will carry out the histological studies. ACRTH assisted in the clinical trial design. CP gave support on the photochemistry of methylene blue. DFTS participated in the design of the study and in coordination, in sequence alignment and drafted the manuscript. All authors read and approved the final manuscript.

\section{Ethics approval and consent to participate}

The project was submitted to the Committee for Research Ethics of the Nove de Julho University, and was approved with CAAE number 34715314.6.3001.0069 issued on 08/27/2014. The trial it was registrated on ClinicalTrials.gov: NCT02416531.

\section{Consent for publication}

The patients signed the Free and Informed Consent, which contains the permission for publication of their images for academic research purposes.

\section{Competing interests}

The authors declare that they have no competing interests.

\section{Publisher's Note}

Springer Nature remains neutral with regard to jurisdictional claims in published maps and institutional affiliations.

\section{Author details}

'Postgraduate Program in Biophotonics Applied to Health Sciences, Nove de Julho University/UNINOVE, 249 Vergueiro Street, Liberdade, São Paulo, SP 01504-001, Brazil. érola Byington Hospital, 683 Brig. Luís Antônio Avenue, Bela Vista, São Paulo, SP 01318-000, Brazil. ${ }^{3}$ Postgraduate Program in
Medicine, Nove de Julho University/UNINOVE, 249 Vergueiro Street Liberdade, São Paulo, SP 01504-001, Brazil. ${ }^{4}$ ABC Medical School and Padre Anchieta Teaching Hospital, 470 Silva Jardim Street, Centre, São Bernardo do Campo, SP 09715-090, Brazil.

Received: 8 March 2016 Accepted: 1 August 2017

Published online: 10 August 2017

\section{References}

1. Kreuter A, Wischnewski J, Terras S, Altmeyer P, Stucker M, Gambichler T. Coexistence of lichen sclerosus and morphea: A retrospective analysis of 472 patients with localized scleroderma from a German tertiary referral center. J Am Acad Dermatol. 2012;67(6):1157-62.

2. Oyama N, Chan I, Neill SM, Hamada T, South AP, Wessagowit V, Wojnarowska F, D'Cruz D, Hughes GJ, Black MM, et al. Autoantibodies to extracellular matrix protein 1 in lichen sclerosus. Lancet. 2003;362(9378):118-23.

3. Gambichler T, Kammann S, Tigges C, Kobus S, Skrygan M, Meier JJ, Kohler CU, Scola N, Stucker M, Bechara FG, et al. Cell cycle regulation and proliferation in lichen sclerosus. Regul Pept. 2011;167(2-3):209-14.

4. Terlou A, Santegoets LAM, van der Meijden WI, Heijmans-Antonissen C, Swagemakers SMA, van der Spek PJ, Ewing PC, van Beurden M, Helmerhorst TJM, Blok LJ. An Autoimmune Phenotype in Vulvar Lichen Sclerosus and Lichen Planus: A Th1 Response and High Levels of Micro RNA-155. J Investig Dermatol. 2012;132(3):658-66.

5. Gambichler T, Terras S, Kreuter A, Skrygan M. Altered global methylation and hydroxymethylation status in vulvar lichen sclerosus: further support for epigenetic mechanisms. Br J Dermatol. 2014;170(3):687-93.

6. Perez-Lopez FR, Ceausu I, Depypere H, Erel CT, Lambrinoudaki I, Rees M, Schenck-Gustafsson K, Tremollieres F, van der Schouw YT, Simoncini T. EMAS clinical guide: Vulvar lichen sclerosus in peri and postmenopausal women. Maturitas. 2013:74(3):279-82.

7. Murphy R. Lichen Sclerosus. Dermatol Clin. 2010;28(4):707-15.

8. Selim MA, Hoang MP. A Histologic Review of Vulvar Inflammatory Dermatoses and Intraepithelial Neoplasm. Dermatol Clin. 2010;28(4):649-67.

9. Lipkin D, Kwon Y. Therapies and Nursing Care of Women with Vulvar Dermatologic Disorders. Jognn-Journal of Obstetric Gynecologic and Neonatal. Nursing. 2014:43(2):246-52

10. Burrows LJ, Creasey A, Goldstein AT. The Treatment of Vulvar Lichen Sclerosus and Female Sexual Dysfunction. J Sexual Med. 2011:8(1):219-22.

11. Monsalvez V, Rivera R, Vanaclocha F. Lichen sclerosus. Actas Dermosifiliogr. 2010;101(1):31-8.

12. Brodrick B, Belkin ZR, Goldstein AT. Influence of treatments on prognosis for vulvar lichen sclerosus: facts and controversies. Clin Dermatol. 2013;31(6):780-6.

13. Hantschmann P, Sterzer S, Jeschke U, Friese K. P 53 expression in vulvar carcinoma, vulvar intraepithelial neoplasia, squamous cell hyperplasia and lichen sclerosus. Anticancer Res. 2005;25(3A):1739-45.

14. Thorstensen KA, Birenbaum DL. Recognition and management of vulvar dermatologic conditions: lichen sclerosus, lichen planus, and lichen simplex chronicus. J Midwifery Womens Health. 2012;57(3):260-75.

15. Terras S, Gambichler T, Moritz RKC, Stucker M, Kreuter A. UV-A1 Phototherapy vs Clobetasol Propionate, $0.05 \%$, in the Treatment of Vulvar Lichen Sclerosus A Randomized Clinical Trial. Jama Dermatol. 2014;150(6):621-7.

16. Biniszkiewicz T, Olejek A, Kozak-Darmas I, Sieron A. Therapeutic effects of 5ALA-induced photodynamic therapy in vulvar lichen sclerosus. Photodiagn Photodyn Ther. 2005;2(2):157-60

17. Hillemanns P, Untch M, Prove F, Baumgartner R, Hillemanns M, Korell M Photodynamic therapy of vulvar lichen sclerosus with 5-aminolevulinic acid. Obstet Gynecol. 1999;93(1):71-4.

18. Osiecka BJ, Nockowski P, Jurczyszyn K, Ziolkowski P. Photodynamic therapy of vulvar lichen sclerosus et atrophicus in a woman with hypothyreosis Case report. Photodiagn Photodyn Ther. 2012;9(2):186-8.

19. Romero A, Hernandez-Nunez A, Cordoba-Guijarro S, Arias-Palomo D, Borbujo-Martinez J. Treatment of recalcitrant erosive vulvar lichen sclerosus with photodynamic therapy. J Am Acad Dermatol. 2007;57(2):S46-7.

20. Sotiriou E, Panagiotidou D, loannidis D. An open trial of 5-aminolevulinic acid photodynamic therapy for vulvar lichen sclerosus. Eur J Obstet Gynecol Reprod Biol. 2008;141(2):187-8

21. Belotto RA, RCM F, Santos RE, Assumpção B, Chavantes MC, DFT S. Photobiomodulation Is More Effective As The Current Treatment Of Vulvar Lichen Sclerosus? Lasers Surg Med. 2016;48 (Supplement):62. 
22. Olejek A, Olszak-Wasik K, Steplewska K, Horak S, Zamlynski J, Kozak-Darmas I, Gabriel A. Efficacy of PDT in vulvar LS treatment based on immunohistochemical analysis of CD3, CD4, CD8, CD57, Granzyme B and Fascin expression. Przeglad Menopauzalny. 2013;12(2):155-8.

23. Olejek A, Steplewska K, Gabriel A, Kozak-Darmas I, Jarek A, Kellas-Sleczka S, Bydlinski F, Sieron-Stoltny K, Horak S, Chelmicki A, et al. Efficacy of Photodynamic Therapy in Vulvar Lichen Sclerosus Treatment Based on Immunohistochemical Analysis of CD34, CD44, Myelin Basic Protein, and Ki67 Antibodies. Int J Gynecol Cancer. 2010;20(5):879-87.

24. Avci P, Gupta A, Sadasivam M, Vecchio D, Pam Z, Pam N, Hamblin MR. LowLevel Laser (Light) Therapy (LLLT) in Skin: Stimulating, Healing, Restoring. Semin Cutan Med Surg. 2013;32(1):41-52.

25. Silva DFT, Gomes ASL, Vidal BD, Ribeiro MS. Birefringence and Second Harmonic Generation on Tendon Collagen Following Red Linearly Polarized Laser Irradiation. Ann Biomed Eng. 2013;41(4):752-62.

26. Idre/UCLA. Institute for digital research and education from University of California. How is effect size used in power analysis? Viewed: 14 February 2017. https://stats.idre.ucla.edu/other/mult-pkg/faq/general/effectsizepower/faghow-is-effect-size-used-in-power-analysis/.

27. Ascencio M, Collinet $P$, Cosson M, Vinatier $D$, Mordon S. The place of photodynamic therapy in gynecology. Gynecol Obstet Fertil. 2007;35(11):1155-65.

28. Taub AF. Photodynamic therapy: Other uses. Dermatol Clin. 2007:25(1):101-9.

29. Morton CA. How to optimise topical photodynamic therapy in dermatology. Photodiagn Photodyn Ther. 2006;3(2):112-5.

30. Kushibiki T, Hirasawa T, Okawa S, Ishihara M. Regulation of miRNA Expression by Low-Level Laser Therapy (LLLT) and Photodynamic Therapy (PDT). Int J Mol Sci. 2013;14(7):13542-58.

31. Joensen J, Demmink JH, Johnson MI, Iversen W, Lopes-Martins RAB, Bjordal JM. The Thermal Effects of Therapeutic Lasers with 810 and $904 \mathrm{~nm}$ Wavelengths on Human Skin. Photomed Laser Surg. 2011;29(3):145-53.

32. Watson MK, Cazzini P, Mayer J, Gottdenker N, Reavill D, Parry N, Fox JG, Sakamoto K. Histology and immunohistochemistry of severe inflammatory bowel disease versus lymphoma in the ferret (Mustela putorius furo). J Vet Diagn Investig. 2016;28(3):198-206.

33. Farrell AM, Dean D, Millard PR, Charnock FM, Wojnarowska F. Cytokine alterations in lichen sclerosus: an immunohistochemical study. Br J Dermatol. 2006:155(5):931-40

34. Kauppila S, Kotila V, Sci L, Knuuti E, Vare PO, Vittaniemi P, Nissi R. The effect of topical pimecrolimus on inflammatory infiltrate in vulvar lichen sclerosus. Am J Obstet Gynecol. 2010;202(2):181e181-4.

35. Balbino CA, Pereira LM, Curi R. Mecanismos envolvidos na cicatrização: uma revisão. Braz J Pharm Sci. 2005;41(1):27-51.

36. Gambichler T, Belz D, Terras S, Kreuter A. Humoral and cell-mediated autoimmunity in lichen sclerosus. Br J Dermatol. 2013;169(1):183-4.

37. Yeh $\mathrm{NG}, \mathrm{Wu} \mathrm{CH}$, Cheng TC. Light-emitting diodes-Their potential in biomedical applications. Renew Sustain Energy Rev. 2010;14(8):2161-6,

38. Hunter M, Backman V, Popescu G, Kalashnikov M, Boone CW, Wax A, Gopal V, Badizadegan K, Stoner GD, Feld MS. Tissue self-affinity and polarized light scattering in the Born approximation: A new model for precancer detection. Phys Rev Lett. 2006;97(13):138102-6.

39. Bish SF, Rajaram N, Nichols B, Tunnel JW. Development of a noncontact diffuse optical spectroscopy probe for measuring tissue optical properties. J Biomed Opt. 2011;16(12):120505.120501-3.

40. Zonios G, Dimou A. Light scattering spectroscopy of human skin in vivo. Opt Express. 2009;17(3):1256-67.

41. Zhong X, Wang J, Shi R, Zhu D. Reflectance spectroscopy for evaluating optical clearing efficacy of skin in vivo In Tuchin W, Duncan DD, Larin KV, Leahy MJ, Wang RK, eds. Bellingham: Dynamics and Fluctuations in Biomedical Photonics X. Proc. of SPIE. 2013; vol 8580: 85800P85801$85800 P 85806$

42. Savenkov SN, Oberemok EA, Mamilov SA, Esman SS, Asimov MM Characteristics of Light Scattering by Normal and Modified Areas of Skin Tissue. J Appl Spectrosc. 2011;78(1):87-94.

\section{Submit your next manuscript to BioMed Central and we will help you at every step:}

- We accept pre-submission inquiries

- Our selector tool helps you to find the most relevant journal

- We provide round the clock customer support

- Convenient online submission

- Thorough peer review

- Inclusion in PubMed and all major indexing services

- Maximum visibility for your research

Submit your manuscript at www.biomedcentral.com/submit
Biomed Central 